\title{
Chapter 37 \\ RRR Cut to Reduce Financing Problems for Companies
}

In China's current economic situation, a RRR cut will help better solve corporate financing problems and boost investment to expand production, thereby driving economic growth.

The Chinese government has clearly stated that it will adopt an active fiscal policy and a prudent monetary policy. The PBC is expected in 2020 to maintain a normal monetary policy with greater countercyclical adjustments, as progress has been made in economic structural adjustment and financial-risk control.

Under China's monetary policy direction, interest rate cuts are more likely to be adopted. Even if cuts in RRR are made, banks may still be reluctant to offer loans.

The pricing of interest rates should first be made on the loan side. After setting a relatively low loan interest rate, companies would be willing to take loans from banks to increase investment in their operations.

More importantly, monetary policy in 2020 should also focus on the monetary policy transmission mechanism so as to allow the results of interest rate and RRR cuts to be passed on to the market more effectively.

In order to stimulate the economy, a supportive fiscal policy is also needed alongside interest rate cuts, including local special debt and more tax and fee reductions.

Source: Global Times, Jan 01-2020. 